\title{
Onset of action of loratadine/montelukast combination in subjects with seasonal allergic rhinitis in the environmental exposure unit
}

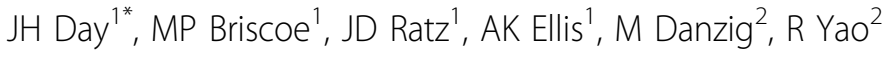 \\ From Canadian Society of Allergy and Clinical Immunology Annual Scientific Meeting 2009 \\ Halifax, Canada. 22-25 October 2009
}

\section{Background}

Onset of action is recognized as an important pharmacologic property of allergic rhinitis medications and can be reliably determined under the controlled conditions of the Environmental Exposure Unit (EEU).

\section{Objective}

To evaluate the onset of action of loratadine/montelukast $(10 \mathrm{mg} / 10 \mathrm{mg})$ versus placebo in subjects with ragweed-induced seasonal allergic rhinitis (SAR).

\section{Methods}

A single-center, double-blind, parallel-group study of ragweed-sensitive allergic rhinitis subjects $(\mathrm{N}=310)$, performed in the EEU. Subjects were exposed to ragweed pollen in the EEU and symptoms were recorded at 30, 60,90 , and 120 minutes prior to a single dose of loratadine/montelukast or placebo. After dosing, symptoms were recorded for 4 hours - at 15-minute intervals for the first 2 hours and 30-minute intervals for the final 2 hours. The primary endpoint was the time to onset of action for loratadine/montelukast, defined as the first time point at which the mean change from baseline in total symptom score (TSS) for loratadine/montelukast became and remained significantly better than placebo. Secondary endpoints included nasal congestion scores and peak nasal inspiratory flow (PNIF).

\section{Results}

The onset of action of loratadine/montelukast for TSS was 1 hour 15 minutes ( $\mathrm{p}=0.005$ versus placebo). Loratadine/montelukast reduced nasal congestion as indicated

\footnotetext{
* Correspondence: dayj@kgh.kari.net

'Department of Medicine, Queen's University and Division of Allergy \&

Immunology, Kingston General Hospital, Kingston, ON, Canada
}

by significant improvements in both the nasal congestion score $(\mathrm{p}=0.011)$ and PNIF measurements $(\mathrm{p}=0.007)$ within 1 hour 15 minutes post dose. The incidence of treatment-emergent adverse events was similar between groups.

\section{Conclusion}

The onset of action following treatment with loratadine/ montelukast was 1 hour 15 minutes for TSS, as well as for nasal congestion. Loratadine/montelukast was well tolerated.

\section{Acknowledgements}

Funding for this study was provided by Schering-Plough/Merck

Pharmaceuticals.

\section{Author details}

'Department of Medicine, Queen's University and Division of Allergy \& Immunology, Kingston General Hospital, Kingston, ON, Canada . ${ }^{2}$ ScheringPlough Research Institute, Kenilworth, NJ, USA.

Published: 12 May 2010

\section{doi:10.1186/1710-1492-6-S1-P29}

Cite this article as: Day et al:: Onset of action of loratadine/montelukast combination in subjects with seasonal allergic rhinitis in the

environmental exposure unit. Allergy, Asthma \& Clinical Immunology 2010 6(Suppl 1):P29. 